harvest. An almost identical ceremonial opens the fire festival in one of the Pardons of Brittany. The Carnival even more surely points to its pagan origin in the celebrations described.

The success of the Institute in stimulating and renewing popular interest in the feste has been much assisted by the revival of the competitions for dialect songs, of which several are quoted. These are sung during the festivals. Local dances and local music played on the people's instruments, such as the pipes and bagpipes of the Abruzzi, have been encouraged. A great impetus was given to interest in the preservation of local costumes on the occasion of the marriage of the Prince of Piedmont, when 4000 individuals, representing all parts of Italy, dressed in the correct traditional costumes, paraded past the
Prince and his bride. The programme, giving the list of costumes, with many illustrations, is repeated in the volume.

While the object of the Institute is practical so far as it aims at the promotion and preservation of popular art and festivals, it does not neglect the interests of the student of custom. Coloured photographs have been taken of all the peasant costumes and of a large number of the more important festivals. Some have also been filmed. A national committee is being set up in collaboration with the League of Nations for the scientific study of Italian folklore. In the meantime the student of folklore will find much to interest him in the Institute's publication, while he will register a debt of gratitude for its respect for tradition.

\title{
Research in the Metropolitan-Vickers Laboratories
}

$\mathrm{T}^{\mathrm{H}}$ E Metropolitan-Vickers Research Department at Trafford Park, Manchester, during last year has been making increasingly important researches to find the scientific data forming the basis of engineering development. It has continued its researches on the effect of high temperatures on the materials used in turbine construction and on the slow rate "creep" tensile tests on steels of various compositions and of various shapes. The effects of thermal action which were found to make steel brittle have been investigated in the case of alloy steels. The high-frequency furnace equipment of the Department has been found most useful in connexion with experiments on the properties of molybdenum steels. As there is a great demand for accurate data about the thermal characteristics of metals, very sensitive apparatus was constructed with this end in view. Prolonged investigations were made on the cooling effect of fins fixed on the outside of tubes carrying hot fluids. Experiments were also made on the converse problem of the cooling effect produced when cold water flows in the pipes causing convection currents of cold air.

Work has been continued on chromium plating, and the critical thicknesses of the nickel and chromium necessary to ensure protection of brass and steel have been determined. Considerable difficulty had been experienced in the plating of high carbon spring steel, but satisfactory coatings can now be obtained on this type of material. The application of cadmium plating as a corrosion resistant has been extended to various processes used in the shops.

Much electrical and magnetic research work has been done in the Metropolitan-Vickers laboratories. The heating of parts of steel structures due to the eddy currents induced in them by conductors carrying large alternating currents in their neighbourhood has been investigated and methods have been devised for avoiding the production of this local heating in the structures. Theoretical and experimental investigations have been carried out to settle questions which arise in the design of high-pressure voltmeters. Continuous research is also being carried out with regard to the cooling radiators used on transformers. The work on core losses has been carried out up to cores of $30,000 \mathrm{kva}$. Other problems discussed in connexion with transformers show the great demands made on the physical knowledge and mathematical skill of the experimenters. They discuss, for example, the distribution of the transient voltages in the coil windings, the effects of magnetic fields on the performance of precision current transformers, the design of high-frequency transformers and Petersen coils for the protection of overhead networks. A 50,000-volt 10,000-frequency transformer has been constructed and satisfactorily operated.

The research on the best heat treatment for magnet steels intended to be used in meters has been completed, and so also has the effect of current impulses on permanent magnets. Three experimental acoustical investigations have been completed for the engineers of the Mersey tunnel, and experimental work has been carried out on methods of preventing the noise made by fans. Preliminary tests were made on the $500-\mathrm{kw}$. valve used at the P.O. Radio Station at Rugby, and it was run up until its output was $520 \mathrm{kw}$. The use of radio waves of lengths about one metre-' quasioptical' waves-is being actively investigated and is said to be promising.

\section{Specificity in Catalysis}

$\mathrm{IN}^{\mathrm{N}}$ the thirty-third Robert Boyle Lecture, Sir Frederick Gowland Hopkins deals with the "Problems of Specificity in Biochemical Catalysis" (Humphrey Milford: Oxford, 1931). He points out that the isolation of biological products and the determination of their constitution are not the endpoints of biochemical research, but rather steps on the path to the investigation of the dynamic events of metabolism in the living cell. In these events catalysts play an important part. Owing to their specificity it appears that there must be a large variety within the confines of a single cell : the acceptance of this conclusion presents to many an intellectual difficulty, which Sir Frederick considers may bo profitably discussed anew in the light of the fresh facts which are now available.

After a brief reference to the hydrolytic enzymes, of which a great variety is known, usually one for each stage in the hydrolysis of any complex molecule, recent work on oxidation is reviewed. Many oxidations are carried out by dehydrogenases which activate the hydrogen in the oxidisable molecule so that it can be taken up by molecular oxygen or other hydrogen acceptor. The xanthine oxidase can transfer hydrogen direct to molecular oxygen: other dehydrogenases can transfer it direct to an acceptor such as methylene blue, but not to oxygen until the latter has also been activated. Keilin's cytochrome,

No. 3252, VoL. 129] 
an iron-pyrrol compound, plays an important part here: activated by indophenoloxidase, it acts as an intermediate carrier of hydrogen to oxygen from the various substrates activated by the dehydrogenases.

Warburg considers that his respiratory enzyme, again an iron-pyrrol derivative, controls the whole field of oxidations. It shows no spectrum, in contrast to cytochrome, but forms reversible combinations with carbon monoxide as well as oxygen, the former of which is decomposed by light. By examining the effectiveness of different wave-lengths in restoring respiration after it had been inhibited by carbon monoxide, Warburg was able to determine the absorption spectrum of the enzyme, since light must be absorbed by the carbon monoxide compound in pro. portion to its effectiveness in dissociating it.

Another path for the transport of hydrogen to oxygen is that associated with the reduction and oxidation of glutathione. Quantitatively it is less prominent than the cytochrome path, but it is essential to the normality of the cell. The cytoplasm of the latter appears to be a lyophil colloidal system in which the micellæ or particles which form the internal phase must be diverse in respect of their surfaces, and probably no small proportion of these surfaces have catalytic properties. Considering the size of the cell and that as much as 75 per cent of cytoplasm is water, of which much is free, it may be assumed that diffusion, as known in macro systems, plays only a negligible part in the velocity of change here, and that contacts between substrate molecules and dispersed particles with catalytic surfaces must continually occur. In such a system a multiplicity of reactions does not appear impossible, whilst the immense numbers of cells in a tissue permit of macroscopic quantities being metabolised.

\section{Sir Ambrose Fleming and the Physical Society of London}

THE meeting of the Physical Society held on Feb. 19 marked an event which is probably unique in the history of learned societies. If we open the Society's first minute book (which has fortunately been preserved) we find that the young Society held its first business meeting on Feb. 14, 1874, when, 29 members being present, a list of officers was drawn up. Dr. J. H. Gladstone, F.R.S., father-in-law of the present Prime Minister, was elected to the presidential chair; Profs. Grylls Adams and Carey Foster were appointed as vice-presidents ; Dr. E. Atkinson and Prof. A. W. Reinold were joint secretaries, and-the holder of an office which has fallen into abeyance-Prof. Frederick Guthrie was appointed as the Society's demonstrator.

The next record on the minutes must be transcribed literatim. It reads :- "A mèeting of the Society was held in the Physical Laboratory, South Kensington Museum, at 3 P.M. on Saturday, March 21st [1874], Dr. Gladstone in the chair. There were about 35 members present. The chairman gave a brief description of the objects and organisation of the Society, and noticed the very favourable circumstances under which the Society originated as compared with those attending the origin of its parent, the Royal Society. He announced that 99 gentlemen had already expressed their desire to join the Society as original members."

"J. A. Fleming, B.Sc., read a paper on the new Contact Theory of the Galvanic Cell. . . . Professor F. Guthrie exhibited experiments illustrating the distribution of a galvanic current on entering and leaving a conducting medium." . . .

"Prof. G. C. Foster, Dr. Wright, and Dr. Gladstone took part in the discussion of the communications."

Can any other society produce such a record ? It may be that a greater span of years separated Liveing's first and last papers read before the Cambridge Literary and Philosophical Society, but we know of no other instance in which the reader of the first paper at the first scientific meeting of a society has survived to communicate a paper to the society nearly sixty years later.

Inspection of the list of members published in 1930 shows that, of the founder fellows, four-Armstrong, Fleming, Schuster, and Unwin-are still with us. Lodge joined the Society in February 1875, and of those who entered the ranks in the 'seventies, fourteen still remained at the time of publication of the list consulted. President and Council have long since
disappeared-Carey Foster was probably the last survivor of the original officers-but it would be in. teresting to know if any of the early members were present when "J. A. Fleming, B.Sc." presented his paper.

It is a far cry from the contact theories of 1875 to the wave mechanics of 1932, and Sir Ambrose Fleming has not only made history in this interval, but also still holds a place on the stage of contemporary events. $\mathrm{He}$ has read some thirty-five papers before the Society, and his latest paper, on "Electrons and Light Quanta", admirably illustrates the conservation of his powers as teacher and experimenter.

In his introductory section, Sir Ambrose states, clearly and succinctly, the fundamental facts concerning the antinomies, which, even though as yet un. solved, have almost ceased to perplex us. He calculates the value of the mean energy density of bright sunlight at earth distance, and, using four methods, he obtains: from the mean of 10 equidistant ordinates of the Planck curve, 48 ; from the solar constant, 45 ; from the Stefan constant, 54 ; from the integration of the Planck equation, 55: all expressed in micro-ergs per cubic centimetre. As the illumination of bright sunlight is about 13,000 candle-feet at normal incidence on a white surface, it is possible to estimate the radiation density of other light beams and the average number of photons per cubic centimetre.

Experimentally, Sir Ambrose proceeded to investigate the question, which he states thus: "If then a beam of light can in any way be regarded as a stream of photons or light quanta each having energy and mass, and if the wave energy is electromagnetic in nature, the question arises whether a stream of electrons moving along a beam of light would have their velocity increased or diminished according as they moved with or against the direction of propagation of the light".

As a preliminary experiment with an arc lamp showed no result, Sir Ambrose employed a powerful beam of X-rays. The source of electrons was a special form of Fleming thermionic valve with a dullemitter filament and two grid anodes of rectangular section fixed on either side. Hence if "a beam of radiation was passed transversely across the valve the electrons on one side of the filament moved against the radiation and on the other side with it ". A simple circuit was arranged which would show by means of a differential galvanometer whether the

No. 3252, VoL. 129] 